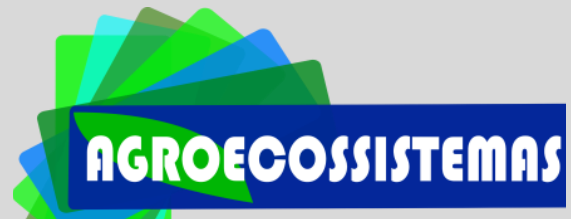

Núcleo de Meio Ambiente Universidade Federal do Pará

Rua Augusto Corrêa, 01, Guamá Belém, Pará, Brasil

https://periodicos.ufpa.br/index.php/agroecossistemas

Thais Esllem Silva Matos

Universidade Federal do Sul e Sudeste do Pará thais.esllem@gmail.com

Ismael Alves Amorim

Universidade Federal do Sul e Sudeste do Pará ismaelamorim93@gmail.com

Diego de Macedo Rodrigues Universidade Federal do Sul e Sudeste do Pará diegomacedo@unifesspa.edu.br

Érica de Jesus Silva Universidade Federal do Sul e Sudeste do Pará ericamicaelli@gmail.com

Recebido em: 2018-10-19 Avaliado em: 2019-08-14 Aceito em: 2019-09-25

\section{AVALIAÇÃO DA SOBREVIVÊNCIA DO AÇAIZEIRO, CULTIVAR BRS- PARÁ, EM ÁREA DE PRESERVAÇÃO PERMANENTE EM SÃO DOMINGOS DO ARAGUAIA-PA}

RESUMO: As Áreas de Preservação Permanente (APP) são áreas encontradas ao longo de curso de água e são constituídas pela flora e fauna e pelos recursos hídricos. Além, disso desempenham importantes funções ecológicas e biológicas para a preservação dos recursos hídricos de uma região, como proteção contra erosão. Mesmo sendo comprovada a importância dessas áreas, elas não são poupadas das intervenções antrópicas. Neste contexto, o objetivo desta pesquisa foi avaliar a sobrevivência do açaizeiro cultivar BRS - Pará, em uma área experimental de Preservação Permanente-APP, da Fazenda Cristalina, em São Domingos do Araguaia-PA. Foram utilizadas quatro parcelas de açaizeiro, com dimensão de $24 \mathrm{~m} \times 12 \mathrm{~m}$, as parcelas foram distribuídas casualmente ao longo do córrego, cada uma contendo 81 plantas e foram avaliadas as 20 plantas centrais. 0 estudo foi realizado durante 10 meses e as avaliações foram a cada 60 dias, sendo nos meses de janeiro a outubro de 2015. O parâmetro avaliado foi à sobrevivência e os dados coletados em campo foram organizados em planilhas do Microsoft Excel e no programa Sisvar. Em relação à taxa de sobrevivência houve diferença entre os meses avaliados, a menor sobrevivência foi no período de menor precipitação. Isso evidencia que as condições das subáreas e pluviosidade influenciaram as mudas de diferentes formas.

PALAVRAS-CHAVE: Degradação, Ecossistema ripário, Recomposição vegetal.

\section{EVALUATION OF THE SURVIVAL OF AÇAIZEIRO, CULTIVAR BRS-PARÁ, IN THE PERMANENT PRESERVATION AREA IN SÃO DOMINGOS DO ARAGUAIA-PA}

ABSTRACT: Areas of Permanent Preservation (APP) are areas found along a water course and are constituted by 
flora and fauna and water resources. In addition, they play important ecological and biological functions for the preservation of the water resources of a region, as protection against erosion. While the importance of these areas is proven, they are not spared from human intervention. In this context, the objective of this research was to evaluate the survival of the cultivar açaizeiro BRS - Pará, in an experimental area of Permanent Preservation - APP, of Fazenda Cristalina, in São Domingos do Araguaia PA.Four plots of açaizeiro were used, with dimensions of $24 \times 12 \mathrm{~m}$, as the plots were supplied along the stream, with a total of 81 plants and were evaluated as 20 central plants of açaizeiro. The test was done during 10 months and was evaluated over a period of 60 days, from January to October 2015. The results were spring and field data were organized in Microsoft Excel spreadsheets and in the Sisvar program. In relation to the virus rate unbound between the months due, less resistance is lower. Evidencing that the conditions of subareas and reported impact the seedlings in different ways.

KEYWORDS: Degradation, Recomposition vegetal, Ripario ecosystem.

\section{EVALUACIÓN DE LA SUPERVIVENCIA DE AÇAIZEIRO EN UN ÁREA DE CONSERVACIÓN PERMANENTE EN SÃO DOMINGOS DO ARAGUAIA-PA}

RESUMEN: Las áreas de preservación permanente (PPA) son áreas que se encuentran a lo largo del curso de agua y están formadas por flora y fauna y recursos hídricos. Además, desempeñan importantes funciones ecológicas y biológicas para la preservación de los recursos hídricos de una región, como la protección contra la erosión. Incluso si se prueba la importancia de estas áreas, no se libran de las intervenciones antrópicas. En este contexto, el objetivo de esta investigación fue evaluar la supervivencia del cultivar BRS - Pará, en un área experimental de Preservación Permanente-APP, Fazenda Cristalina, en São Domingos do AraguaiaPA. Se utilizaron cuatro parcelas de açaí, que miden $24 \times 12 \mathrm{~m}$, las parcelas se distribuyeron aleatoriamente a lo largo del arroyo, cada una con 81 plantas y se evaluaron las 20 plantas centrales. El estudio se realizó durante 10 meses y las evaluaciones fueron cada 60 días, de enero a octubre de 2015. El parámetro evaluado fue la supervivencia y los datos recopilados en el campo se organizaron en hojas de cálculo de Microsoft Excel y el programa Sisvar. En cuanto a la tasa de supervivencia, hubo una diferencia entre los meses evaluados, la supervivencia más baja fue en el período de menor precipitación. Esto muestra que las condiciones de la subárea y la lluvia influyeron en las plántulas de diferentes maneras.

PALABRAS CLAVES: Degradación, Ecosistema ribereño, Recomposición de la planta. 


\section{INTRODUÇÃO}

De acordo com o Código Florestal (Lei 12.651/2012) Áreas de Preservações Permanentes (APPs) são áreas protegidas, coberta ou não por vegetação nativa, com a função ambiental de preservar os recursos hídricos, a paisagem, a estabilidade geológica e a biodiversidade, facilitar o fluxo gênico de fauna e flora, proteger o solo e assegurar o bem-estar das populações humana. Além disso, as APPs são áreas situadas às margens de córrego, rios e nascente; nos altos de morros; nas encostas com declividade acentuada e nas bordas de tabuleiros ou chapadas com inclinação maior que 45; e nas áreas em altitude superior a 1.800 metros, com qualquer cobertura $\neg$ vegetal.

As Áreas de Preservação Permanente - APP sofrem pressão antrópica por uma serie de fatores, são as áreas diretamente mais afetadas na construção de hidrelétricas, aberturas de estradas, para a implantação de culturas agrícolas e de pastagens (CRESTANA, 2006).
Neste sentido, Galvão (2000), afirma que é possível realizar a recuperação de área de preservação permanente, por meio do plantio de espécies nativas. E segundo Goudel et al., (2011), - plantio do açaizeiro (Euterpe oleracea Mart.), que é nativo da Amazônia, apresenta atributos ideais para ser usada na recuperação de passivos ambientais em Áreas de Preservação Permanente.

Em trabalhos realizados por Lunz et al. (2014) foi evidenciado que o açaizeiro, cultivar BRS - Pará, encontrase em estudo é uma nova espécie e ainda é avaliado seu desempenho em campo nas condiç̃̃es edafoclimáticas da Amazônia. Neste contexto, o objetivo dessa pesquisa foi avaliar a sobrevivência do açaizeiro cultivar BRSPará, em Área de Preservação Permanente- APP em São Domingos do Araguaia-Pará.

\section{MATERIAL E MÉTODOS}

O experimento foi realizado na Fazenda Cristalina, no Projeto Biomas que é executado pela EMBRAPA (Empresa Brasileira de Pesquisa 
Agropecuária) no município de São Domingos do Araguaia-PA. A área experimental está inserida no subprojeto de pesquisa AM10: Reabilitação estrutural de ecossistemas ripários em microbacias na região do médio Rio Tocantins.

A área do experimento é uma área de preservação permanente degradada principalmente pela pecuária extensiva. O córrego da área experimental tendo cerca de $3 \mathrm{~m}$ de largura, é uma nascente tributário da bacia do Córrego Fortaleza, sendo esse um córrego maior que fica na proximidade da propriedade que deságua no Rio Araguaia - Tocantins.

Em relação ao clima, segundo Köppen, a microrregião de Marabá possui temperatura anual de $28^{\circ} \mathrm{C}$, a média anual de precipitação pluvial é de 1.925,7 mm, 77\% das precipitações ocorrem entre dezembro e abril e o período de menor pluviosidade vai de Junho a Outubro (Figura 1). O período de maior insolação vai de Maio a Agosto, dezembro é o menor (ALMEIDA, 2007).

Figura 1. Distribuição média mensal de precipitação (PPT) em Marabá/PA. Estação no 82.562, observadas no ano de 2015.

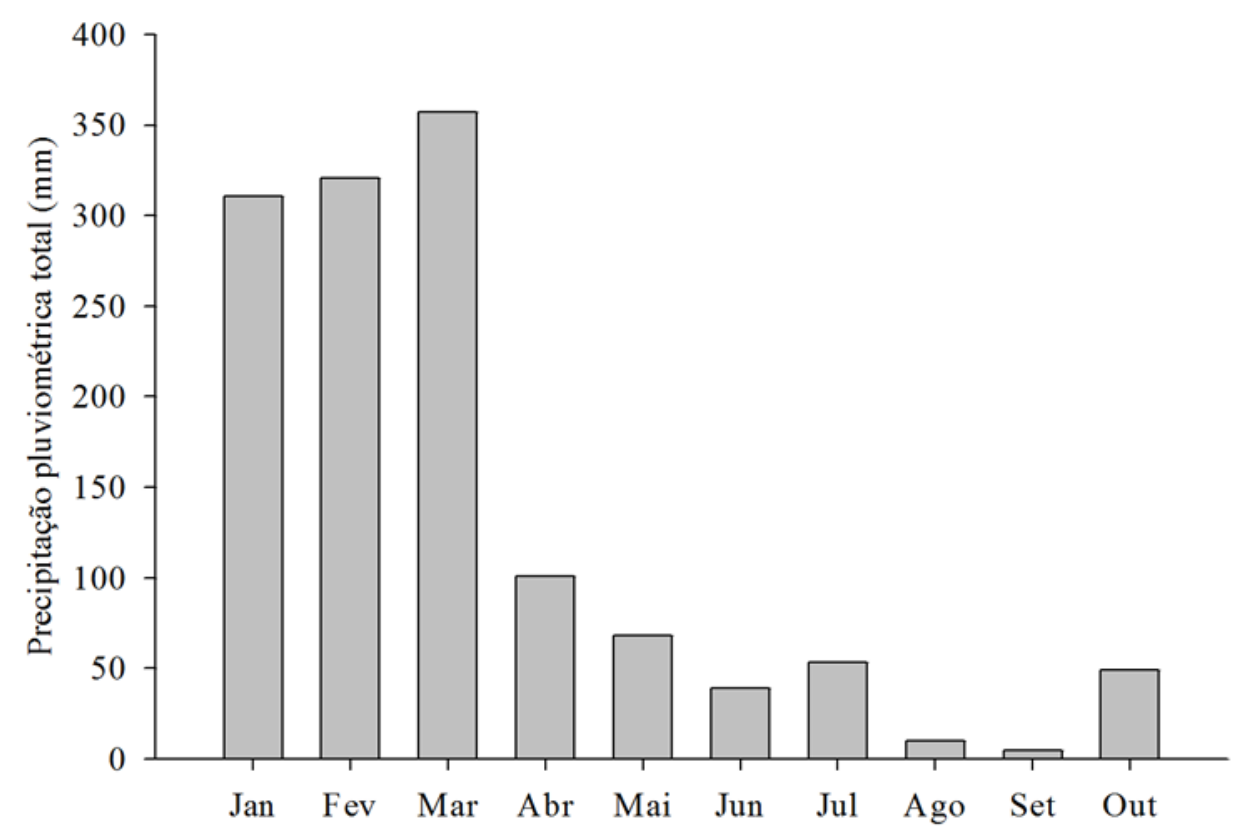

Fonte: INMET(2015). 
O experimento foi implantado em delineamento inteiramente casualizado em quatro subáreas experimentais. Cada subárea apresentava diferentes combinações de condições de campo como solo, luminosidade, vegetação e umidade. As parcelas experimentais apresentaram tamanho de $12 \times 24 \mathrm{~m}$ e foram demarcadas ao longo do córrego existente na área, uma parcela em cada subárea. Em cada parcela foram plantadas 81 plantas.

As mudas de açaizeiro (E. oleracea) cultivar BRS-Pará foram plantadas no início da estação chuvosa em dezembro de 2014, contendo uma média de altura de $30 \mathrm{~cm}$ e o espaçamento foi de 1,5 $\mathrm{x}$ 2,0 m, cada cova contendo $20 \mathrm{~cm}$ de diâmetro e $40 \mathrm{~cm}$ profundidade.

A avaliação da sobrevivência foi realizada ao longo de 10 meses, no período compreendido entre janeiro e outubro de 2015. As coletas dos dados ocorreram a cada 60 dias (bimestralmente), dessa forma as avaliações ocorreram em janeiro, março, maio, julho e setembro de 2015, totalizando cinco avaliações. Foram avaliadas as 20 plantas centrais de cada parcela experimental, deixando linhas de bordadura.

A sobrevivência das mudas foi avaliada levando-se em consideração o critério de sobrevivência\morte a onde foi considerada muda morta quando se apresentava seca, sem folhas e caule verdes e sem fixação da raiz no solo. Os dados foram sistematizados em planilha do Microsoft Excel. Os gráficos apresentados foram elaborados pelo Sigmaplot versão 2012.

\section{RESULTADOS E DISCUSSÃO}

Observou-se que as menores taxas de sobrevivência ocorreram no período de menor pluviosidade (Junho a Setembro, ver figura 1), diminuindo a pluviosidade também reduziu a sobrevivência, como ilustra a figura 2. Estes dados corroboram com Sousa (2006), que observou no açaizeiro, na região de Bragança-PA, que a maior taxa de sobrevivência 87,21\%, ocorreu no período de maior pluviosidade e menor temperatura, já a maior taxa de mortalidade de 96,61\%, foi observada no período de menor precipitação e alta temperatura. 
Figura 2. Sobrevivência do açaizeiro nas quatro subáreas ao longo dos períodos avaliados.

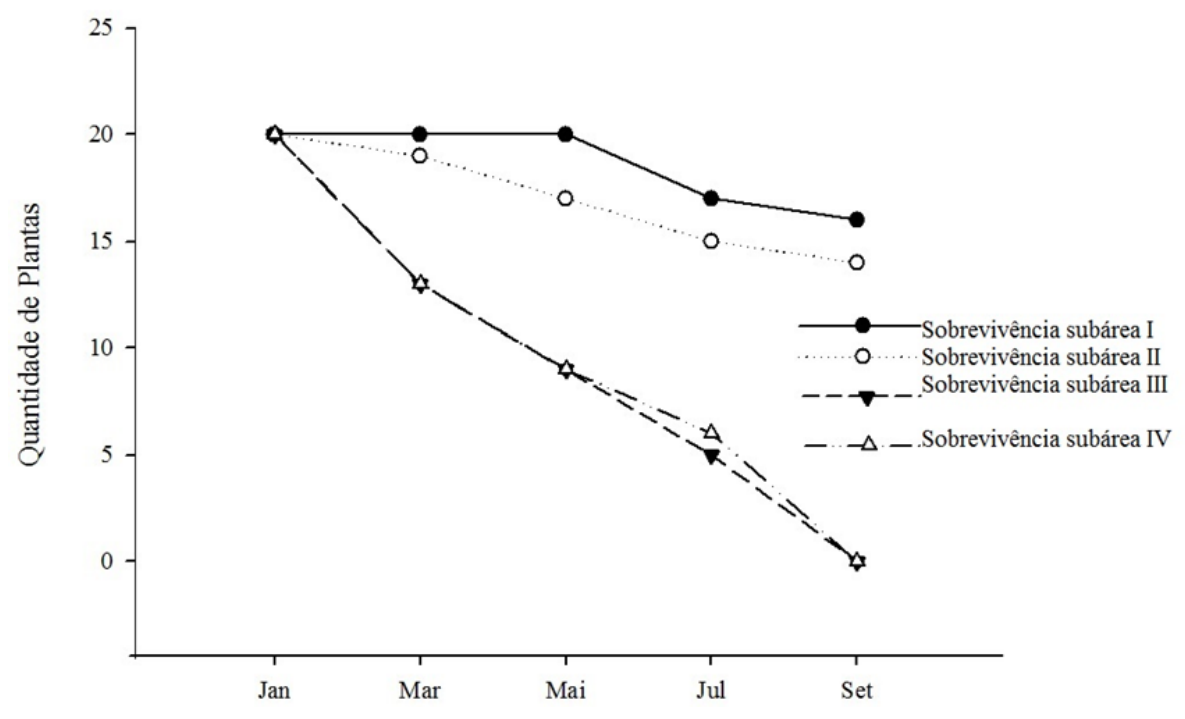

A subárea I, em janeiro teve $100 \%$ de sobrevivência, diminuindo em setembro para $80 \%$. Já na subárea II, em setembro constatou dentre as subáreas o segundo maior percentual (70\%) de sobrevivência.

Em estudo realizado por Sousa (2002) com Euterpe oleracea em recuperação de área de preservação permanente, foi observado taxa de sobrevivência abaixo de 33\%. Neste contexto, os estudos da sobrevivência do açaizeiro em condições de campo, constataram taxa de sobrevivência inferior as das subáreas I e II, que obtiveram respectivamente $80 \%$ e $70 \%$.
Esse percentual de sobrevivência pode ser atribuído, a um conjunto de fatores. Dentre eles, o fato de que as subáreas | e || estão próximas do córrego e possui vegetação secundária que realiza o sombreamento das subáreas. Uma parte da subárea I se mantém inundada no inverno, tendo assim uma boa disponibilidade hídrica nos meses de estudo.

Segundo Sousa (2006), a sombreamento influencia na sobrevivência e mortalidade das palmeiras, como também foi relatado por Tonetti e Negrelle (2001) que registraram $60 \%$ e $40 \%$ de mortalidade 
de Euterpe edulis, respectivamente, em ambiente natural com alta luminosidade.

A sobrevivência na subárea III foi de 100\% em janeiro, já no mês de março foi de 65\%, nos períodos de maior déficit hídrico a sobrevivência foi diminuindo, apresentando em maio $45 \%$, julho 25\% e setembro 0\%.

Segundo Sousa e Jardim (2007), o açaizeiro em condições de déficit hídrico e alta temperatura têm dificuldade na absorção de água, ocasionando perda de turgescência das células e desidratação, podendo culminar na morte da planta. Nesse sentido, a fisiologia do açaizeiro em condições de déficit hídrico, pode ter influenciado no resultado das subáreas III e IV.

A mortalidade total das plantas nestas subáreas pode ser devido às condições edafoclimáticas, juntamente com o pequeno porte com que as mudas foram plantadas, com a média de altura de $30 \mathrm{~cm}$. Conforme Farias Neto et al. (2006), a altura ideal para o açaizeiro ser plantado em campo é de 40 a 60 cm, medidos a partir do colo da planta.

Apesar do local em estudo ser uma Área de Preservação Permanente - APP, as subáreas III e IV estão distantes cerca de 15 e 10 metros do córrego, respectivamente e a disponibilidade hídrica para as plantas foi somente através da precipitação. Assim, fica evidente que o açaizeiro cultivar BRS - Pará é uma espécie desenvolvida para área de terra firme, porém é necessário irrigação no período de baixa precipitação (OLIVEIRA; FARIAS NETO, 2004).

\section{CONCLUSÃO}

A taxa de sobrevivência nas subáreas e meses de avaliações foi influenciada pelos fatores abióticos da área. Houve diferença entre os meses avaliados, a menor sobrevivência foi no período de menor precipitação. Isso evidencia que as condições das subáreas e a pluviosidade influenciaram as mudas de diferentes formas, sendo os aspectos analisados considerados satisfatórios.

\section{REFERÊNCIAS}

ALMEIDA, M. F. Caracterização agrometeorológica do município de Marabá. 200777 f. Trabalho de Conclusão de Curso (Graduação) Colegiado de Ciências Agrárias, Campus 
Universitário de Marabá, Universidade Federal do Pará, Marabá, PA, 2007.

CRESTANA, M. S. M. (ORG) et al. Florestas - Sistema de recuperação com essências nativas, produção de mudas e legislações, $2^{\circ}$ ed. Campinas, Editora CATI, 2006.p 100-111.

BRASIL. Lei no 12.651, de 25 de maio de 2012. Código Florestal. Dispõe sobre a proteção da vegetação nativa. Disponível em < http://www.planalto.gov.br/ccivil_03/_a to2011-2014/2012/lei/12651.htm>.

Acesso em 9 de set de 2018.

FARIAS NETO, J. T. MÜLLER, C. H.; CARVALHO A. A.; MATOS, J. E. U.; VIÉGAS, I. J. Sistema de produção do Açaí, Embrapa Amazônia Oriental., 4 $2^{a}$ Edição Dez./2006.

GALVÃO, A. P. M. Reflorestamento de propriedades rurais para fins produtivos e ambientais: um guia para ações municipais e regionais. Colombo- PR Editora EMBRAPAISBN85-7383-081-6, 2000 p. 19-55.

GOUDEL, F.; FARIAS, M.; REIS, T; MILLER, P. R. M. O potencial de uso da palmeira juçara Euterpe edulis Mart. Revista Agropecuária Catarinense, v.24, n.3, nov. 2011.

LUNZ, A. M. P.; PADILHA, M. S.; MESQUITA, J. F. B. MACHADO, M. L. C.; SILVA JUNIOR, E. C. S. Avaliação do crescimento de açaizeiro (Euterpe oleracea Mart.) no Estado do Acre. In: CONGRESSO BRASILEIRO DE FRUTICULTURA, 22., 2012, Bento Gonçalves: Anais... Bento Gonçalves:
Sociedade Brasileira de Fruticultura. SBF 2012. CD-ROM.

OLIVEIRA, M. S. P.; FARIAS NETO, J. T. de. Cultivar BRS - Pará: açaizeiro para a produção de frutos em terra firme. Belém-PA: (Circular técnica, 114). Embrapa Amazônia Oriental 2004.

SOUSA, C. C. Estabelecimento e crescimento inicial de espécies florestais em plantios de recuperação de matas de galerias do Distrito Federal. 2002. 98 f. Dissertação de Mestrado-Universidade de Brasília. Faculdade de Tecnologia. Departamento de Engenharia Florestal (EFL/FT/UnB). Brasília, 2002.

SOUSA, L. A. S. Desenvolvimento de plantas jovens de açaizeiro (Euterpe oleracea Mart.) plantado em área com vegetação secundária (capoeira) na localidade de Benjamin Constante, município de Bragança, PA. 2006. Tese de mestrado. Ciências Biológicas. Universidade Federal Rural da Amazônia. Belém - PA, 2006.

SOUSA, L. A. S.; JARDIM, M. A. G.; Sobrevivência e Mortalidade de Plântulas de Açaizeiro (Euterpe oleracea Mart.) Cultivadas em Capoeira no Nordeste Paraense. Revista Brasileira de Biociências, Porto Alegre, v. 5, supl. 1, p. 255-257, jul. 2007.

TONETTI, E.L.; NEGRELLE, R.R.B. Dinâmica de banco de sementes de plântulas de palmiteiro em ambiente natural. Revista Scientia Agrária,2(1):1-7. 2001. 